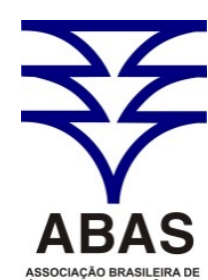

ASSOCIACAOA BRASILEIRADE www.abas.org

\section{O QUE SÃO POÇOS? \\ UM PANORAMA DAS TERMINOLOGIAS UTILIZADAS PARA CAPTAÇÕES DE ÁGUAS SUBTERRÂNEAS}

\author{
WHAT ARE WELLS? \\ OVERVIEW OF THE TERMS USED TO GROUNDWATER ABSTRACTION
}

Mickaelon Belchior Vasconcelos ${ }^{1,2}$

Artigo recebido em: 18/10/2016 e aceito para publicação em: 15/02/2017.

DOI: http://dx.doi.org/10.14295/ras.v31i2.28666

\begin{abstract}
Resumo: Os avanços dos estudos de hidrologia subterrânea muitas vezes deixam de lado alguns conceitos essenciais e básicos referentes à área de conhecimento. As unidades de captações de águas subterrâneas, também conhecidas como poços, recebem diversas denominações nos mais diversos estudos e pesquisas em regiões distintas. Palavras como artesiano, freático, dentre outras, correlatas com os estudos com águas subterrâneas, são muitas vezes utilizadas de forma errônea na literatura existente. A falta de uma padronização de termos pode gerar dificuldades na interpretação dos dados em determinadas situações por causa da diferenciação das linguagens e, consequentemente, falta de compatibilidade entre banco de dados. Este trabalho objetiva traçar um panorama das terminologias utilizadas para denominar as unidades de captação de águas subterrâneas e, com isso, gerar uma discussão sobre a uniformização de uma nomenclatura única. A metodologia adotada na execução deste estudo foi realizada basicamente através da análise de trabalhos anteriores. Foi verificado que o assunto da "falta de uma padronização" já foi abordado por outros pesquisadores, porém a ausência de uma nomenclatura específica para as unidades de captação de águas subterrâneas continua existindo.
\end{abstract}

Palavras-chave: Poços tubulares. Poços escavados. Terminologias de poços.

\begin{abstract}
The advances of studies of groundwater hydrology often leave aside some essential and basic concepts related to the area of knowledge. Groundwater catchment units, also known as wells, receive different denominations in the most diverse studies and researches in different regions. Words such as artesian, phreatic, among others, correlated with studies with groundwater, are often misused in the existing literature. The lack of a standardization of terms can cause difficulties in interpreting the data in certain situations because of the differentiation of languages and, consequently, lack of compatibility between databases. The objective of this work is to outline the terminologies used to designate groundwater catchment units and, thus, to generate a discussion on the standardization of a single nomenclature. The methodology adopted in the execution of this study was basically performed through the analysis of previous studies. It was found that the subject of "lack of standardization" has already been addressed by other researchers, but the lack of a specific nomenclature for groundwater capture units continues to exist.
\end{abstract}

Keywords: Tubular wells. Hand dug wells. Terminology of wells.

\section{INTRODUÇÃO}

As águas subterrâneas geralmente não possuem tanta visibilidade quanto as águas superficiais por estarem sempre escondidas dos olhares da população em geral. Se um rio possui uma água fluindo em determinada direção, com uma coloração alterada, facilmente isso é identificado. Para verificar as características das águas subterrâneas (direção de fluxo e alterações visíveis na cor da água) serão necessários a perfuração de poços ou então, encontrar surgências naturais. Representando cerca de 33,79\% das águas não oceânicas contidas no globo terrestre, as águas subterrâneas são muito abundantes se comparadas às águas de rios e lagos com 0,56\% de toda água não oceânica do globo terrestre (VON SPERLING, 2006).

Os primeiros registros da humanidade

\footnotetext{
${ }^{1}$ CPRM - Serviço Geológico do Brasil, Residência de Fortaleza-REFO. E-mail: (mickvasconcelos@yahoo.com.br)

${ }^{2}$ Unifor-Universidade de Fortaleza.
} 
do aproveitamento da água subterrânea são incertos datando aproximadamente de 2.500 a. C., relatando construções de poços e túneis, ou seja, sistemas que possuíam uma interconexão entre poços através de túneis, conhecidos como qanats ou kanats (ENGLISH, 1998). Estes sistemas de captação foram construídos inicialmente na Pérsia, atualmente Irã, estendendo-se por todas as regiões vizinhas da península Arábica, até a Europa. Estas formas de captações de águas receberam diversos nomes como; kettara, foggara, kizamá, fagir, jattará, mayrá, puquio dentre outras variações nos dialetos existentes nas diversas regiões em que foram construídos (ABDIN, 2006; ENGLISH, 1968; FITTS, 2002; LIGHTFOOT, 1996; LIGHTFOOT, 2000; TOLMAN, 1937; WESSELS, 2005).

As terminologias recebem adaptações regionais, principalmente quanto ao idioma empregado, porém diante de uma mesma região, supõe-se que as terminologias técnicas para caracterização de processos ou dispositivos sejam as mesmas.

A variação dos termos foi abordada por Daubrée (1887) no qual cita as variações das nomenclaturas em alguns locais da Europa:

en français, on l'appele nappe d'eau des puits (Belgrand) nappe d'infiltration (Delesse) couche aquifère libre, nappe liquide (Verstraeten); en allemand, le nom de Groundwasser est très, de même que celui groundwater Angleterre; elles ont été aussi appelée en anglais water level (Geikie), ground spring (Prestwich) et waterplain (Dana); en hollandais, Welwater; en Italie, notamment en Sicile, acqua di livello (cau de niveau), et vulgairement acqua di centro, etc. (DAUBRÉE, 1887, p. 19).

Norton (1897, p. 125) em seu trabalho desenvolvido no estado de Iowa, nos Estados Unidos da América, identifica as diferentes denominações dadas aos poços: bored wells, deep wells, artesian wells, artesian fountains, and even "bubbling" wells; all these phrases have been applied to the same phenomena. Cita também a variação de nomes existentes na literatura científica francesa como: puits foré, puits arésiens, foutainnes artésiennes, foutaines artificieles, foutaines jaillissantes des puits forés.

Um termo técnico para ser adotado, deve ser aceito pelos profissionais da área e que seja utilizado e empregado nos trabalhos que abordem o assunto.

A palavra "poço" pode estar associada geralmente a duas finalidades básicas de acordo com a sua utilização (VASCONCELOS, 2014):

- Para um pesquisador, trata-se de uma "janela" de acesso direto ao aquífero, sendo a fonte de muitas informações e;

- Para a população em geral, representa uma fonte de abastecimento hídrico.

\subsection{A necessidade de uma padronização das terminologias}

Para a formação de um glossário de termos técnicos são necessárias diversas discussões e que o termo nele inserido seja usual e aceito por estudiosos e profissionais da área.

Um exemplo da necessidade de definição de um termo específico foi abordado por Cederstron (1964) quando sugeriu encontrar um termo para substituir a palavra "log" de um poço, que mais tarde seria usualmente utilizada para referir-se ao "perfil" de um poço.

Uma das definições pioneiras para poços foi feita por Meizer (1923) que define um poço no sentido "stricto" do termo como sendo uma escavação artificial que obtém um fluido dos interstícios de rochas ou solos que o mesmo penetra; "tradução do autor". No mesmo trabalho aborda que os poços podem ser classificados de acordo com os fluidos que produzem, tais como: poço de óleo, poço de gás, poço de salmouras e poço de água. Meizer, op. cit., apresenta algumas classificações como inverted well e combination well, sendo abordado os diferentes termos que denotam água abaixo da superfície, como ground water, underground water, subsurface water e 
phreatic water.

$\mathrm{Na}$ abordagem sobre o assunto de abastecimento hídrico municipal através de poços, Waterman (1938) faz uma breve classificação das captações de águas subterrâneas existentes, considerando dois critérios para classificação: profundidade e método construtivo.

Segundo Lohman et al. (1988), o trabalho de Meinzer em 1923 inspirou a criação de um Comitê para discutir termos usuais em águas subterrâneas.

Alguns trabalhos como Fuller (1906b), Struckmeier e Margat (1995), Diniz (2012), Ment (1998), Diniz et al. (2012), subsidiam metodologias para a construção/elaboração de mapas hidrogeológicos, que no caso contemplará também a representação gráfica dos poços de captação de águas subterrâneas.

As unidades de captação de águas subterrâneas são denominadas, na maior parte dos casos de poços, porém com suas variadas adjetivações. Fuller (1906a) faz uma avaliação detalhada sobre o uso do termo artesiano, tanto nos Estados Unidos da América como na Europa. A variação de terminologias já foi, provavelmente, abordada de forma pioneira no Brasil, pelo engenheiro Azevedo Netto (1960) em sua publicação "Poços Artesianos - Uma questão de Metodologia" na qual faz o seguinte comentário: "a nomenclatura de poços profundos é um exemplo típico da falta de uma terminologia adequada em nosso meio". Azevedo Netto, op. cit., também faz o seguinte registro:

\footnotetext{
Sobre o assunto manifesta-se com brilhantíssimo o ilustre Professor Carvalho Lopes: Vale por bem aqui combater o conceito popular e mesmo arraigado entre pessoas cultas de que Artesiano é sinônimo de jorrante. O conceito técnico de "artesianismo" é o fato do lençol estar preso sob pressão... (AZEVEDO NETTO, 1960, p.59).
}

Diante disso, verifica-se a necessidade de se buscar uma padronização dos termos adotados e, consequentemente, evitar erros em termos interpretativos na avaliação da caracterização do abastecimento de água de determinada região e, consequentemente, reduzir as incertezas traçando um modelo hidrológico mais próximo da realidade.

A formação de terminologias já foi discutida ao longo do tempo, sendo, por exemplo, abordada por Rodrigues (1977) quando trata das captações de águas subterrâneas na Grande São Paulo: comenta que existem duas espécies de poços, os rasos e os profundos, sendo os rasos construídos com ferramentas manuais e os profundos com maquinaria especial.

Algumas publicações abordam especificamente os termos relativos aos poços, podendo ser citadas duas a seguir:

- Chamberlin (1885), na publicação "The Requisite and Qualyfing Conditions of Artesian Wells” faz uma análise dos poços artesianos e comenta que o termo "poço artesiano" é aplicado somente àqueles que têm o fluxo até a superfície, porém infelizmente o termo é frequentemente utilizado para poços profundos que não fluem, ou seja, o termo não é utilizado corretamente. Verifica-se então uma abordagem sobre a má utilização dos termos técnicos relativos aos poços.

- Lohman et al. (1988), na publicação "Definitions of Selected Ground-Water Terms Revisions and Conceptual Refinements", considera artesiano como sinônimo de confinado, definindo que um poço artesiano deriva de águas artesianas ou de corpos de água confinados (tradução do autor).

A complexidade envolvida em relação aos estudos com poços é apresentada na Figura 1 onde estão citados alguns fatores existentes para a construção de um poço, bem como alguns atributos técnicos que podem ser obtidos a partir do mesmo. 


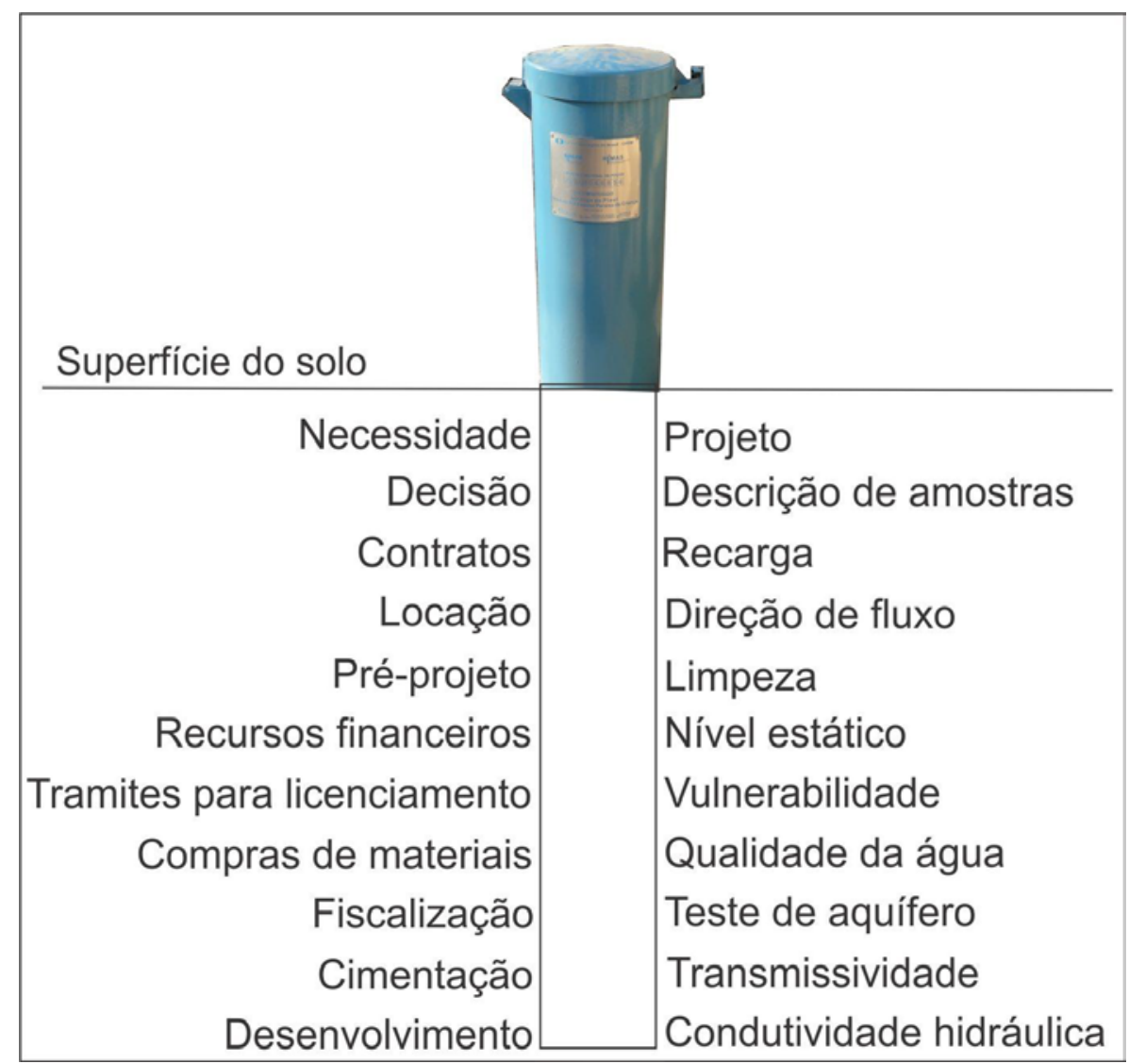

Figura 1 - Analogia de um poço tubular com fatores e atributos envolvidos desde a necessidade da construção até as informações geradas após a sua conclusão e operação. Fonte: elaborado pelo autor.

Figure 1 - Analogy of a tubular well with factors and attributes involved from the construction need to the information generated after its completion and operation. Source: prepared by the author.

\subsection{A necessidade de registro e armazenamento dos dados de poços} do conhecimento hidrogeológico é apresentado por Machado (2008), que no Brasil, conhecimento este, foi impulsionado entre as décadas de 1950-1960 com a criação da Superintendência de Desenvolvimento do Nordeste (SUDENE) e com a implantação dos primeiros cursos de geologia do Nordeste no Recife e em Salvador (DINIZ; FEITOSA, 2008).

O início das perfurações de poços no Brasil teve início, segundo Rebouças (2000), quando o governo provincial do Ceará, que vigorou no segundo Reinado (1840-1889), foi autorizado a perfurar poços, tendo em vista que os cacimbões (poços escavados) e lagoas que forneciam água para abastecimento da população em Fortaleza, a capital da Província, secavam sob o impacto das secas. A autorização concedida ao Ceará passou a ser exigida por outras províncias, resultando numa rápida proliferação da perfuração de poços na região Nordeste.

A necessidade de se o rganizar as informações de obras realizadas levou o órgão do governo federal, Inspetoria Federal de Obras Contra as Secas (IFOCS), a publicar uma relação de poços tubulares, particulares e públicos construídos pelo órgão no Nordeste brasileiro desde o ano de 1912, dentre outras obras como açudes, estradas de rodagem e de ferro (WARING, 1923). Já em 1934 era inserida a relação de poços construídos nos boletins do IFOCS, (IFOCS, 1934), contendo dados de qualidade de água, quantidade de poços utilizados e abandonados, profundidade total de cada perfuração e o total perfurado nos estados do Ceará, Rio Grande do Norte, Pernambuco, Sergipe e Bahia. 
Um método de registro das informações básicas dos poços perfurados pelo Departamento Nacional de Obras Contra as Secas (DNOCS) é apresentado na Figura 2, uma no ano de 1958 (Figura 2B) e outra no ano de 1963 (Figura 2A), no qual são gravados os dados na estrutura de alvenaria

onde o poço está situado. Desta forma, além da informação estar provavelmente tabulada em um registro na forma de um relatório a mesma encontra-se gravada físicamente no local da obra.

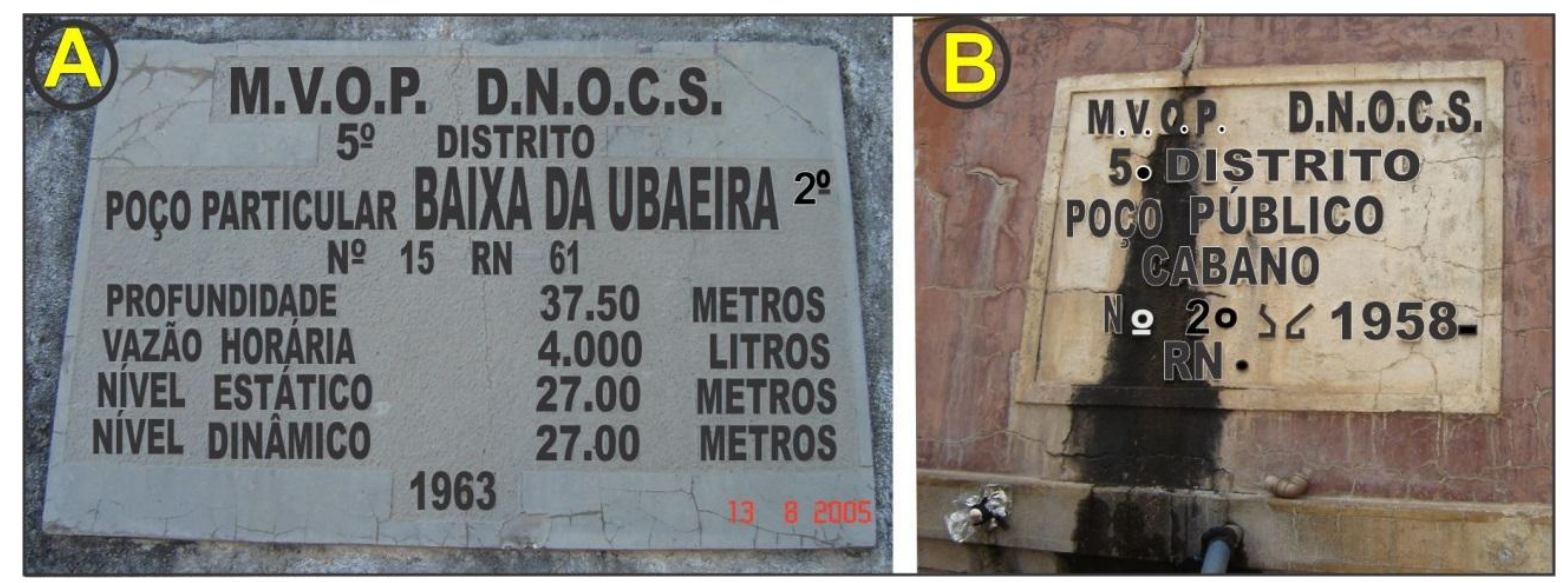

Figura 2 - Registros gravados na parede em cimento da estrutura de distribuição de água. Região dos municípios de Açu e Ipanguaçu no estado do Rio Grande do Norte (agosto de 2005): A) Poço particular na localidade Baixa da Ubaeira, perfurado em 1963; B) Poço público na localidade de Cabano perfurado em 1958. *O texto em relevo foi realçado pelo autor através de uma edição da imagem, não comprometendo a originalidade da informação. Fonte: elaborado pelo autor.

Figure 2 - Records recorded on the cement wall of the water distribution structure. Region of the municipalities of Açu and Ipanguaçu in the state of Rio Grande do Norte (August 2005): A) Private well in Baixa da Ubaeira, drilled in 1963; B) Public well in the town of Cabano drilled in 1958. * The raised text was highlighted by the author through an edition of the image, not compromising the originality of the information. Source: prepared by the author.

Em 1979 o Departamento Nacional de Produção Mineral (DNPM) iniciou a criação de um Sistema de Informações Hidrogeológicas (SIHIDRO), no qual foi elaborada uma ficha padrão de cadastro de poços para alimentar um banco de dados (MONT'ALVERNE; ALVES, 1984). Esta ficha padrão tinha como objetivo aproveitar informações de bancos de dados já existentes na época, conhecido como Sistema de Banco de Dados das Águas Subterrâneas (SAS), criado para fornecer subsídios sobre os pontos d'água do Nordeste, em particular os poços tubulares (Pinto et al., 1984).

No ano de 1997 a Companhia de Pesquisa de Recursos Minerais (CPRM) com atribuições de Serviço Geológico do Brasil implantou o Sistema de Informações de Águas Subterrâneas (SIAGAS) que compreende, em termos gerais, um cadastro nacional de pontos d'águas disponibilizados livremente em um ambiente de Sistema de Informações Geográficas (SIG) através do endereço eletrônico: www.cprm.gov.br.

A partir do ano de 1998 a CPRM iniciou os trabalhos de cadastramento de poços através do levantamento da infraestrutura hídrica dos estados inseridos no semiárido (CPRM, 1999; 2004; CPRM 2005a; 2005b; 2005c). A organização das informações obtidas em um banco de dados torna-se essencial para a gestão dos recursos hídricos e com as informações geradas pelo cadastro de poços contribuíram para alimentar o banco de dados do SIAGAS. Esse sistema de informações desenvolvido pela CPRM possui o objetivo de coletar, recuperar, consistir, armazenar e difundir dados e informações, para dar suporte às atividades de pesquisas, estudos, planejamentos e gestão dos recursos hídricos (PEIXINHO; LIMA, 2008; NASCIMENTO; 
CARVALHO; PEIXINHO, 2008). Possui uma importância no contexto das políticas públicas como na área da saúde, meio ambiente e recursos hídricos (PEIXINHO; OLIVEIRA, 2004: RIBEIRO, 2008; PEIXINHO; LIMA, 2008), sendo, por exemplo, utilizado por Vasconcelos et al. (2014) para traçar o perfil da densidade de captações de águas subterrâneas no Piauí.

A partir dos estudos realizados por diferentes pesquisadores envolvendo os recursos hídricos subterrâneos, verifica-se que as captações de águas subterrâneas recebem diversas denominações, já abordada por pesquisadores Norte Americanos ou Europeus. No Brasil, são identificados termos como; cacimba, cacimbão, poço amazonas, cisterna, poço profundo, poço raso, poço artesiano entre outros. A falta de uma padronização nacional dos termos gera dificuldades na caracterização e interpretação dos dados em determinadas situações por causa da diferenciação dos conceitos.

\section{OBJETIVOS E ASPECTOS METO- DOLÓGICOS}

Este trabalho possui o objetivo de apresentar um panorama das terminologias referentes às obras de captações de águas subterrâneas através do ordenamento de informações e gerar a discussão baseada em trabalhos específicos sobre 0 assunto, contribuindo para dar suporte ao avanço do conhecimento sobre os recursos hídricos subterrâneos.

O desenvolvimento metodológico foi realizado a partir da compilação de estudos anteriores que abordam as terminologias existentes na área de águas subterrâneas e posterior análise e discussão.

\section{RESULTADOS E DISCUSSÕES}

A partir de uma análise da bibliografia especializada em águas subterrâneas apresentada na introdução deste trabalho, verifica-se, em termos gerais, que a variação de terminologias é evidente. Em decorrência da diversidade das denominações para os poços de captação de águas subterrâneas, faz com que seja necessária uma padronização das denominações. Nos itens a seguir serão apresentadaes as denominações mais usuais para os diferentes propósitos de captações de águas subterrâneas e também considerando os fatores hidráulicos atuantes nos mesmos.

\subsection{Considerações gerais sobre poços não convencionais}

Neste trabalho consideram-se como poços não convencionais, aqueles que possuem a finalidade hidrogeológica ou hidrogeotécnica, porém não necessariamente possuem a finalidade de captar água subterrânea, distanciando assim do tema central deste trabalho.

Os poços de recarga e de observação (pesquisa/monitoramento) são condições especiais, pois mesmo sem possuir a finalidade de abastecimento hídrico, estão inseridos na definição geral de poço, mesmo por se apresentarem em quantidade relativamente menor em relação aos demais. Em decorrência de não se tratar exclusivamente de um poço para captação de água, estes não serão objetos de análises e definições.

Alguns tipos de poços bastante comuns em obras de engenharia quando a água no solo se torna um problema, são os poços jateados também conhecidos como poços ponteiras (VAZ; DOBEREINER, 1998) e, também os poços de alívios. Todos os dois possuem a função básica de realizar um rebaixamento induzido no nível estático das águas subterrâneas. Os poços jateados (jet points ou wellpoints) são perfurados em linha relativamente próximos, basicamente com o auxílio de água pressurizada, introduzindo no solo um tubo que irá posteriormente ser utilizado para captar as águas subterrâneas, rebaixando o lençol freático e propiciar as atividades na obra considerada. Caputo e Caputo (2015) utiliza os termos poços filtrantes ou sistema de poços filtrantes relacionando-os aos poços utilizados para rebaixamento de aquíferos. 
Outros tipos de poços são os poços de alívio, que representam meios utilizados para solucionar problemas de liquefação e consequentemente propiciar a segurança de barramentos de água (barragens, açudes e reservatórios de superfície). Esses poços são construídos, geralmente, no lado jusante das barragens e têm a função de drenar a água que percola pela fundação da barragem de tal forma que reduza as cargas hidráulicas e toda a drenagem seja direcionada para uma estrutura que se tem um controle do escoamento (CARVALHO, 1984; GAIOTO, 2003; HEIDARZEDEH et al., 2013; MASSAD, 2010; SOUZA; SILVA, 1998; US ARMY CORPS OF ENGINEERS, 1992). Esses poços além de possuírem a função de drenos, têm a finalidade de reter os materiais finos e, assim, não gerar instabilidade no terreno.

Muitas vezes, em decorrência da generalização de que a palavra "poço" possa representar somente uma fonte hídrica, podem deixar de lado outros tipos de unidades que também podem ser conhecidas como poços. Os poços de recarga ou injeção e os poços de observação (piezômetros) são também pontos d’água que estão enquadrados na definição de poços.

O trabalho "Legenda para Mapas Hidrogeológicos”, desenvolvido por Leal (1974) para a Superintendência de Desenvolvimento do Nordeste (SUDENE), insere no mesmo, a legenda para poços de recarga, mostrando assim, a ampla abrangência desse levantamento cartográfico.

\subsection{Considerações gerais sobre poços para captação de água}

Nos estudos que possuem a finalidade de caracterizar a infraestrutura hídrica de regiões, os poços de captações de águas subterrâneas podem ser inseridos e generalizados em uma nomenclatura abrangente, sendo denominados de "pontos d'água”. Por definição, os pontos d'água recebem a seguinte denominação: "um lugar, obra civil, ou circunstância que permita o acesso direto ou indireto a um aquífero que considere" (CUSTÓDIO; LLAMAS, 1983, p. 1558), com modificações. Nesse sentido, estão inseridas todas as perfurações existentes, que estão sendo explotadas ou não, abandonadas, fontes naturais (surgências), lagos ou lagunas quando representam afloramentos de aquíferos (CUSTÓDIO; LLAMAS, 1983, com modificações). Em termos gerais, nessa definição são considerados todos os locais que possuem acesso a um aquífero considerado.

De uma forma mais específica, os poços para captação de águas subterrâneas podem ser divididos em dois grupos que, por sua vez, possuem subdivisões segundo o modo de construção, diâmetro, revestimento e pressões hidráulicas atuantes.

\section{- Poços escavados}

Desde os primórdios da colonização do Brasil, as águas subterrâneas vêm sendo captadas por meio de fontes e poços escavados, fazendo parte de muitos monumentos históricos do Período Colonial do Brasil entre 1500-1822 (REBOUÇAS, 2000 com modificações). Os angolanos trazidos como escravos chamavam tais obras (poços escavados) como "kixima" que, com o passar do tempo, foram denominadas de "cacimba", e no Nordeste do Brasil, passou a ser chamado de "cacimbão" (PIUCI, 1986).

Segundo Vasconcelos (2014) os poços escavados são caracterizados por possuírem, geralmente, um diâmetro superior a $0,5 \mathrm{~m}$, com profundidades bastante variadas de um metro a dezenas de metros, dependendo diretamente da litificação da formação geológica. Podem ser divididos em três classes mais específicas: cacimba, cacimbão e amazonas (Figura 3). Essa compartimentação realizada por Vasconcelos (2014) surgiu de estudos anteriores em função da necessidade de caracterizar a infraestrutura hídrica de municípios que tinham os poços escavados como a base principal do abastecimento hídrico (VASCONCELOS et al., 2003; VASCONCELOS, 2004). 

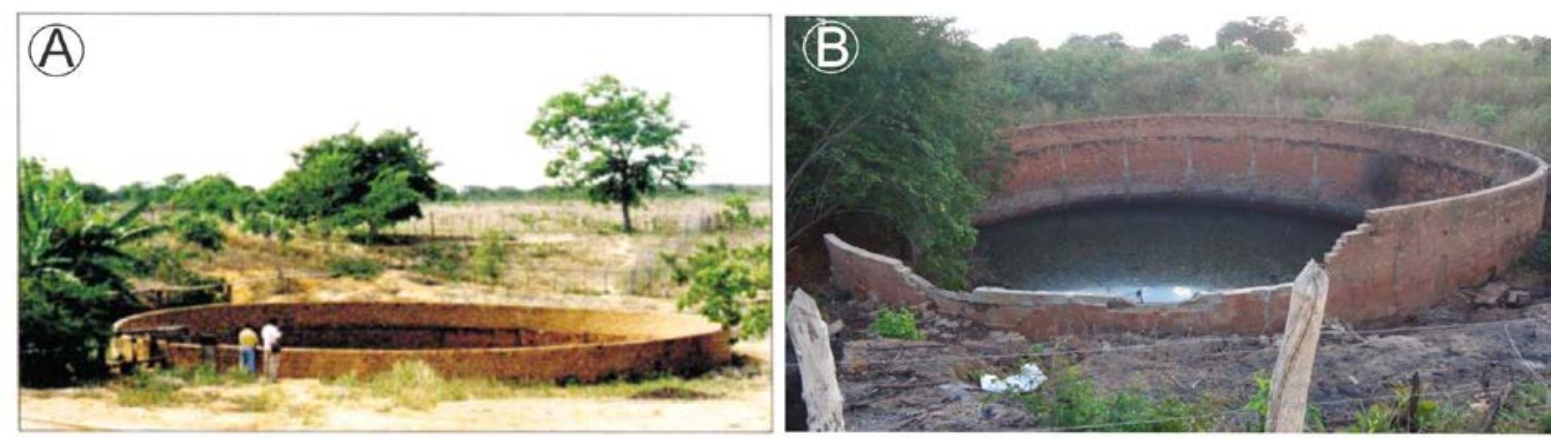

Figura 3 - Poço escavado do tipo amazonas construído na região sul do estado do Ceará: A) Poço na fazenda Estrela no município de Barbalha-CE, com aproximadamente 20,5 m de diâmetro (Fonte: Veríssimo, 1999); B) O mesmo poço escavado tipo amazonas em julho de 2014 (Fonte: elaborado pelo autor).

Figure 3 - Hand dug well type Amazonas built in the southern region of the state of Ceará: A) Well at Estrela farm in the municipality of Barbalha-CE, with approximately $20.5 \mathrm{~m}$ in diameter (Source: Veríssimo, 1999); B) The same hand dug well type Amazonas in July 2014 (Source: elaborated by the author).

Um tipo particular de captação que pode ser encontrado nas margens dos reservatórios superficiais (açudes) e em leitos de rios ou riachos secos são as "cacimbas temporárias” (VASCONCELOS, 2014). Possuem profundidades pouco superiores a $0,5 \mathrm{~m}$ e diâmetros menores do que $0,5 \mathrm{~m}$. Geralmente, esses poços não são considerados nos estudos, sendo excluídos em boa parte das pesquisas, pois em consequência de sua pequena representatividade, ou seja, pequeno diâmetro e profundidade. A exclusão destas formas de captações nos levantamentos de abastecimento hídrico pode mascarar a real fonte de abastecimento hídrico nas diversas regiões, principalmente do semiárido, em períodos de estiagens.

Os poços escavados do tipo cacimbão são unidades de captação de água subterrânea que possuem diâmetro superior a meio metro e inferior a cinco metros, e que possuem um revestimento lateral, que pode ser parcial ou total. Em algumas situações esses poços são fechados com tampas, impedindo assim a identificação da profundidade do revestimento, ou seja, não é possível saber, se é parcial ou se é total. É comum em alguns cacimbões a redução do diâmetro de acordo com a profundidade.

Um caso particular são os poços escavados que possuem um sistema de captação de água por drenos horizontais, ou também chamados de drenos radiais; poços radiais ou poços coletores (TODD; MAYS,
2005). Na Região Nordeste do Brasil algumas captações semelhantes já foram construídas empregando-se filtros espiralados, instalados a céu aberto e com o lençol freático rebaixado. No entanto, o custo de construção é elevado (SOUZA; RIBEIRO, 1986).

Com relação aos poços horizontais, Larsson (1985) cita este tipo de captação utilizado em área de grande relevo para alcançar a estratificação vertical ou zonas de fraturas. Nesse mesmo trabalho apresenta a denominação de poços mistos, no caso são poços tubulares perfurados dentro de um poço escavado, ou seja, um poço dentro de outro poço. No Brasil a denominação "poço misto" é dada aos poços que captam águas em duas zonas diferenciadas como uma água menos profunda em aluviões ou manto de alteração e, posteriormente, em maior profundidade, captando simultaneamente água de rochas fraturadas. O objetivo desses poços mistos é de captar a maior vazão de produção do poço tubular através dos dois aquíferos considerados, um intergranular e outro fraturado.

Com base em uma revisão de conceitos sobre poços Vasconcelos (2014) faz a seguinte definição para um poço: "um sistema geralmente vertical, feito pelo homem, que tem ação em subsuperfície, usado para a captação, recarga ou observação das águas subterrâneas através de mecanismos artificiais ou naturais". 


\section{- Poços tubulares}

Os poços tubulares, como o próprio nome designa, possuem um revestimento tubular, que geralmente pode ser de policloreto de vinila (PVC), PVC geomecânico (SIMABUKURO, 2000) ou aço. O revestimento não é necessariamente total, podendo ser parcial. Os diâmetros são geralmente inferiores a 1 metro, podendo em alguns casos apresentar uma redução do diâmetro à medida que aumenta a profundidade da perfuração. O diâmetro é comumente expresso em polegadas, variando de 2 a 18”, sendo mais comuns os de 6 e 8 polegadas.

Os poços construídos com trado (manual ou mecânico), que penetram poucas profundidades, geralmente menores do que $15 \mathrm{~m}$ e em aquíferos livres são, portanto, classificados como poços tubulares freáticos. São poços obrigatoriamente revestidos por tubos, podendo ser de diversos materiais, como aço, ferro, ou PVC estando localizados predominantemente, em regiões com domínios aluvionares, mantos de alteração e nas partes rebaixadas de áreas de dunas.

Em termos gerais, quando os poços tubulares possuem uma ascensão natural da água dentro do poço, são conhecidos como artesianos. Em decorrência dessa condição, os poços podem ser divididos em dois grupos quanto à carga hidráulica do aquífero:

- Artesiano não jorrante: poço que capta água de aquíferos confinados em que a superfície potenciométrica (carga hidráulica) encontra-se abaixo da superfície topográfica.
- Artesiano jorrante: poço que capta água de aquíferos confinados em que a superfície potenciométrica encontra-se acima da superfície topográfica. Dessa forma, a água chega naturalmente à superfície do terreno sem a necessidade de bombeamento.

Segundo Norton (1897) a palavra artesiano deriva do latim artesium, que equivale a Artois, nome de uma antiga província na França no departamento de Pasde-Calais.

O processo de "artesianismo" trata-se da elevação do nível de água no poço gerado pela pressão das camadas superiores que confinam um determinado aquífero. Se a água eleva-se naturalmente acima da superfície do terreno, este poço será classificado como jorrante e, caso não atinja a superfície do terreno, será classificado como não jorrante. $\mathrm{O}$ jorro de poços artesianos, em alguns casos, pode ser de curta duração, pois a pressão no aquífero confinado pode cessar rapidamente com a explotação do aquífero. Dessa forma, um poço inicialmente classificado como artesiano jorrante, pode passar a ser artesiano não jorrante.

Com a finalidade de facilitar o processo de identificação (classificação) das unidades (obras) de captação de águas subterrâneas foi elaborado um fluxograma apresentado na Figura 4, que faz uma sumarização das principais classificações existentes e uma forma para denominá-las. 


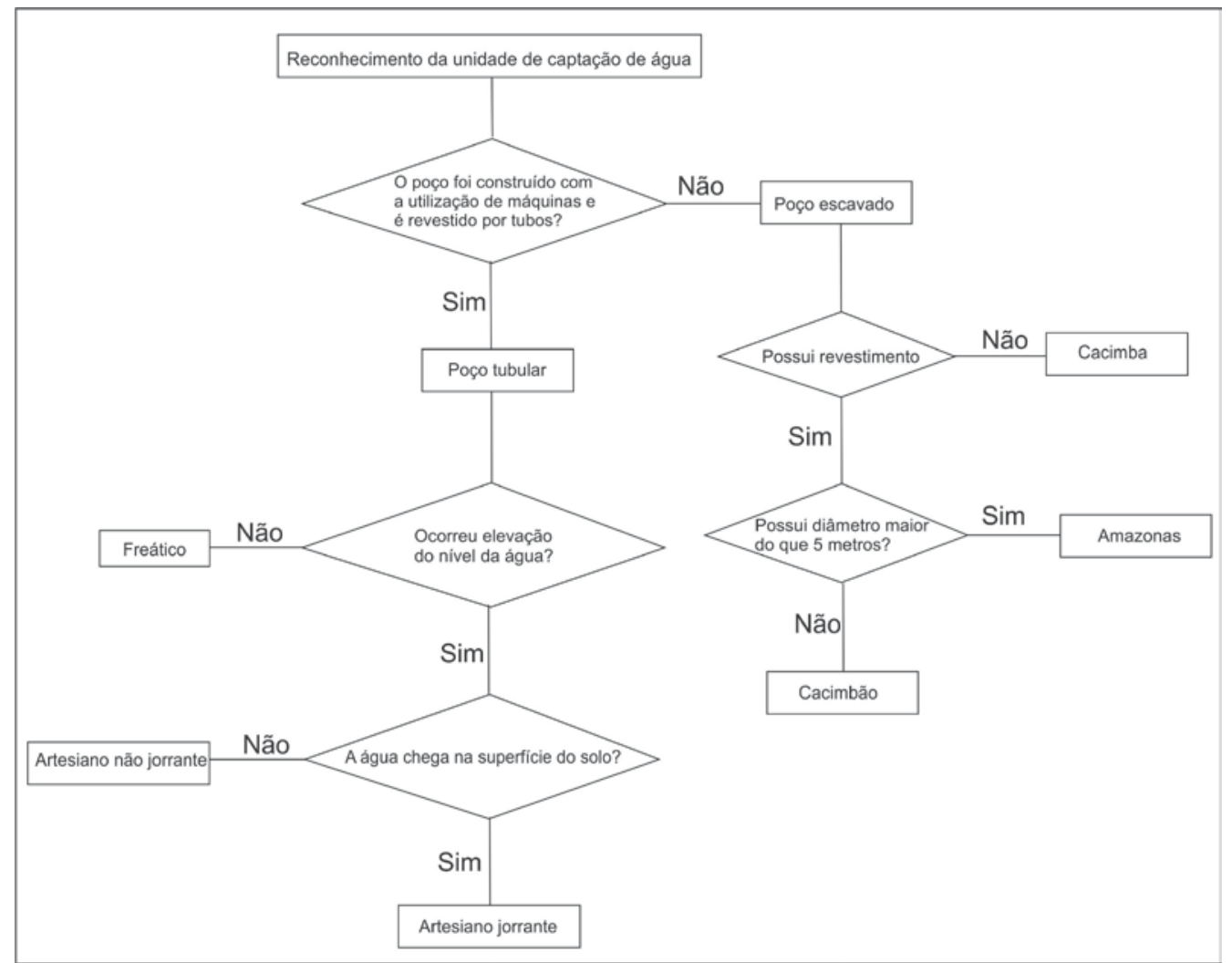

Figura 4 - Fluxograma orientativo para reconhecimento e classificação da unidade de captação de água subterrânea. Fonte: elaborado pelo autor

Figure 4 - Guidance flowchart for recognition and classification of the groundwater catchment unit. Source: prepared by the author

\section{CONSIDERAÇÕES FINAIS}

Verifica-se que com o passar do tempo a uniformização dos termos envolvidos para as obras que captam águas subterrâneas ainda representam um desafio a ser enfrentado e equacionado. A necessidade de uma formulação e padronização da nomenclatura sobre tipos de poços é evidente. A definição relativamente clara para compor os mais diversos estudos irá, consequentemente, proporcionar a possibilidade de integração entre banco de dados de poços e os mais diversos estudos de casos que envolvam captações de águas subterrâneas.

\section{REFERÊNCIAS}

ABDIN, S. Qanats a unique groundwater management tool in arid, 2006. regions: the case of bam region in Iran. In: International symposium on groundwater sustainability (USGWAS), 2006.
AZEVEDO NETTO, J. M.; Poços artesianos. Revista DAE, n. 36, 1960. Disponível em: $<$ http://revistadae.com.br/artigos/artigo_edicao_3 6_n_735.pdf $>$. Acesso em: 05 maio 2016.

CARVAlHO, L. H. Curso de barragens de terra com vistas ao nordeste brasileiro. Ministério do Interior, Departamento de Obras Contra as Secas - DNOCS, 1984. volume 2.

CAPUTO, H. P.; CAPUTO, A. N. Mecânica dos solos e suas aplicações: mecânica das rochas fundações e obras de terra. 7 ed. Rio de Janeiro: LTC, 2016. 560 p. volume 2.

CEDERSTROM, D. J. Geology and groundwater resources of St. Croix.V.I: U. S. Geol. Survey Water Supply paper 1067. 1950. Disponível em: $<$ http://pubs.usgs.gov/wsp/1067/report.pdf $>$. Acesso em 11 jul. 2016.

CEDERSTROM, D. J. Água Subterrânea: uma Introdução. 1964. Rio de Janeiro.

CHAMBERLIN, T. C. The Requisite and qualify- 
ing Conditions of Artesian Wells, 1885. Fifth Ann. Rep. U. S. Geol. Surv. (1883-84), p. 12573, $1885 . \quad$ Disponível em: $<$ https://archive.org/details/requisiteandqua00cha mgoog>. Acesso em: 11 jul. 2016.

CPRM - SERVIÇO GEOLÓGICO DO BRASIL. Atlas dos recursos hídricos subterrâneos do Ceará: programa recenseamento de fontes de abastecimento por água subterrânea no Estado do Ceará. Fortaleza: CPRM, 1999. 1 CD-ROM.

CPRM - SERVIÇO GEOLÓGICO DO BRASIL. Atlas digital dos recursos hídricos subterrâneos do Estado do Piauí. Fortaleza: CPRM; PRODEEM, 2004. 1 CD-ROM.

CPRM - SERVIÇO GEOLÓGICO DO BRASIL (a). Atlas digital dos recursos hídricos subterrâneos do Estado de Alagoas. Recife: CPRM; PRODEEM, 2005. 1 CD-ROM. Projeto Cadastro de Fontes de Abastecimento por Água Subterrânea.

CPRM - SERVIÇO GEOLÓGICO DO BRASIL (b). Atlas digital dos recursos hídricos subterrâneos do Estado da Bahia. Fortaleza: CPRM; PRODEEM, 2005. 1 CD-ROM.

CPRM - SERVIÇO GEOLÓGICO DO BRASIL (c). Atlas digital dos recursos hídricos subterrâneos do Estado de Pernambuco. Recife: CPRM/PRODEEM, 2005. 1 CD-ROM. Projeto Cadastro de Fontes de Abastecimento por Água Subterrânea

CUSTODIO, E.; LLAMAS, M. R. Hidrologia Subterrânea. Ed. Omega, S.A. 2. ed. Barcelona, España. 1983.

DAUBRÉE, A. Les Eaux Souterraines A L'époque Actuelle. Leur Régime, Leur Temperature, Leur Composition, 1887. 1 ed. Paris: Vve C. Dunod. 455 p. Disponível em $<$ http://jubilotheque.upmc.fr/fonds-

geolhist/GH_000422_001/document.pdf name=GH_000422_001_pdf.> acesso em $31 / 12 / 2016$.

DOBEREINER, L.; VAZ, L. F. Tratamento de Maciços Naturais. In: Oliveira, A. M. S.; Brito, S. N. A. Geologia de Engenharia, 1998.

DINIZ, J. A.; FEITOSA, F. A. C. Histórico da atuação dos Órgãos Públicos de Pesquisa de Água Subterrânea na Região Nordeste do Brasil. In: CONGRESSO BRASILEIRO DE ÁGUAS SUBTERRÂNEAS, $\quad 15 ., \quad 2008 . \quad$ Anais... Disponível em: $<$ https://aguassubterraneas.abas.org/asubterraneas /article/view/23729/15800> Acesso em : 22 set. 2015.

DINIZ, et al. 2012 Taxonomia Hidrogeológica Unidades Básicas de Referência. In: CONGRESSO BRASILEIRO DE ÁGUAS SUBTERRÂNEAS, $\quad$ 18., $\quad 2012 . \quad$ Anais... Disponível em: $<$ https://aguassubterraneas.abas.org/asubterraneas /article/view/28287/18400>. Acesso em: $30 \mathrm{dez}$. 2016.

DINIZ, J. A. Metodologia Para el Deserarrollo de Maps Hidrogeológicos. In: CONGRESO LATINOAMERICANO DE HIDROGEOLOGÍA, 11., 2012. Anais... ALHSUD.

DINIZ, J. A. O.; MONTEIRO, A. B.; FEITOSA, F. A. C.; FREITAS, M. A.; PEIXINHO, F. C. Metodologia para Elaboração de Mapas Hidrogeológicos. In: CONGRESSO BRASILEIRO DE ÁGUAS SUBTERRÂNEAS. 17., 2012, Bonito, MS. Resumos Expandidos... Bonito, MS: CABAS, out. 2012. p. 1-4.

DINIZ, J. A. O. Manual de cartografia hidrogeológica. CPRM - Serviço Geológico do Brasil, 2014. CD-ROM.

ENGLISH, P. W. Qanats and Life worlds on Iranian Plateau Villages. In: J. Albert, M. Bernhardsson, R. Kenna (Eds.), Transformation of Middle Eastern Natural Environment, Bulletin Series 103, Yale School of Forestry and Environmental Studies, Yale University Press, 1998, p. 187-205. Disponível em: $<$ http://environment.yale.edu/publicationseries/796.html>. Acesso em: 09 jan. 2017.

FEITOSA, E. C.; FEITOSA, F. A. C. Metodologia Básica de Pesquisa de Água Subterrânea. In: FEITOSA, F. A. C.; MANOEL FILHO, J.; FEITOSA, E. C.; DEMETRIO, J. G. A. (Org.); Hidrogeologia: conceitos e aplicações. 3. ed. Rio de Janeiro: CPRM, LABHID, 2008, $812 \mathrm{p}$ 
FITTS, C. R. Groundwater science. Academic Press, Elsevier, 2002. 450 p.

FULLER, M. L.(a). Significance of the Term "Artesian". 1906. P. 9-15. In: Undergroundwater papers, united states geological survey, water-supply and irrigation paper $n^{\circ} 160$. Disponível

$<$ https://pubs.usgs.gov/wsp/0160/report.pdf>.

Acesso em 02 jul. 2016.

FULLER, M. L.(b). Representation of Wells and Springs on Maps. 1906. p.16-18 In: Underground-Water Papers, United States Geological Survey, Water-Supply and Irrigation Paper, n. 160. Disponível em: $<$ https://pubs.usgs.gov/wsp/0160/report.pdf $>$. Acesso em: 02 jul. 2016.

GAIOTO, N. Introdução ao projeto de barragens de terra e de enrocamento, São Carlos, EESC-USP, 2003.

HEIDARZEDEH, M.; MIRGHASEMI, A. A.; NIROOMAND, $\mathrm{H}$. Construction of relief wells under artesian flow conditions at dam toes: engineering experiences from Karkheh earth dam, Iran. International Journal of Civil Engineering-Geotechnique，2013. Disponível em:

$<$ http://ijce.iust.ac.ir/browse.php?a_id=927\&slc_l ang=en\&sid=1\&ftxt=1>. Acesso em 07 jul. 2016.

IFOCS - Ispetoria Federal de Obras Contra as Secas. Boletim da inspetoria federal de obras contra as secas, v. 1, n. 1. 1934. 48 p.

LOHMAN, S. W.; BENNETT, R. R.; BROWN, R. H.; COOPER, H. H.; DRECHER, W. J.; FERRIS, J. G.; JOHNSON, A. I.; LOHMAN, S. H.; MCGUINESS, C. L.; PIPER, A. M.; RORABAUGH, M. I.; STALLMAN, R. W.; THEIS, C. V. Definitions of selected groundwater terms- revisions and conceptual refinements. United states geological survey, water-supply paper, 1988. Disponível em: < http://pubs.usgs.gov/wsp/wsp_1988/pdf/wsp_198 8.pdf>. Acesso em: 11 jul. 2016.

LARSSON, I. Aguas subterráneas en rocas duras, Proyecto 8.6 do Programa Hidrológico Internacional, UNESCO, 1985. Disponível em: <http://unesdoc.unesco.org/images/0006/000632/ 063230so.pdf> Acesso em: 12 jul. 2016.
LEAL, A. de S. Legenda para mapas hidrogeológicos, Recife - SUDENE - Div. Documentação. 1973. 72p.

LIGHTFOOT, D. R. Syrian qanat Romani: history, ecology, abandonment. Journal of Arid Environments. 1996.

LIGHTFOOT, D. R. The Origin and Diffusion of Qanats in Arábia: New Evidence from the Northern and Southern Peninsula. The Geographical Journal, v. 166, n. 3, p. 215-226, 2000 .

MACHADO, J. L. F. Águas Subterrâneas e poços: uma jornada através dos tempos. Porto Alegre, EST Edições/Suliani-Letra \& Vida, 2008.

MASSAD, F. Obras de Terra: curso básico de geotecnia. 2. ed. Oficina de Textos, 2010.

MENT, A. Cartografia Hidrogeológica. In: FEITOSA, F. A. C.; MANOEL FILHO, J.; FEITOSA, E. C.; DEMETRIO, J. G. A. (Org.); Hidrogeologia: conceitos e aplicações. 3. ed. Rio de Janeiro: CPRM, LABHID, 2008, 812 p. P. 709-723.

MONT'ALVERNE; A. A. F.; ALVES, A. G. Sistema de Informações Hidrogeológicas SIHIDRO do DNPM. In: CONGRESSO BRASILEIRO DE ÁGUAS SUBTERRÂNEAS. 2., 1984. Anais...

MEINZER, O. E. Outline of Ground-Water Hydrology. U. S. Geological Survey Water Supply paper 494. 1923. Disponível em: $<$ http://pubs.usgs.gov/wsp/0494/report.pdf>.

Acesso em 11 jul. 2016.

NASCIMENTO, F. M. F.; CARVALHO, J. E.; PEIXINHO, F. C. Sistema de Informações de Água Subterrânea - SIAGAS Histórico, Desafios e Perspectivas. In: CONGRESSO BRASILEIRO DE ÁGUAS SUBTERRÂNEAS. 15,. 2008. Anais... Natal, 2008. Disponível em: $<$ https://aguassubterraneas.abas.org/asubterraneas /article/view/23834>. Acesso em: 02 jan. 2017.

NORTON, W. H. Artesian Wells of Iowa. Iowa Geological Survey Annual Report: v. 6, p. 113428. Disponível em: $<$ http://ir.uiowa.edu/igsar/vol6/iss1/5>. Acesso em 05 jan. 2017. 
PEIXINHO, F. C.; OLIVEIRA, J. E. C. Sistema de informações de águas subterrâneas - SIAGAS - as suas funcionalidades e importância no contexto das políticas públicas. In: CONGRESSO BRASILEIRO DE ÁGUAS SUBTERRÂNEAS, 13., 2004. Anais..

PEIXINHO, F. C.; LIMA, J. B. Sistema de Informações em Águas Subterrâneas. In: FEITOSA, F. A. C.; MANOEL FILHO, J.; FEITOSA, E. C.; DEMETRIO, J. G. A. (Org.); Hidrogeologia: conceitos e aplicações. 3. ed. Rio de Janeiro: CPRM, LABHID, 2008, 812 p.

PINTO, C. A. M.; VALENÇA, Y. H. A.; CUNHA, R. M. B. Sistema de banco de dados de águas subterrâneas - notícias a nível nacional. In: CONGRESSO BRASILEIRO DE ÁGUAS SUBTERRÂNEAS, 3., 1984. Anais...

PIUCI, J. Elementos Propedêuticos para compreensão das águas subterrâneas rasas ocorrentes na parte oriental da Ilha de MarajóPará. In: CONGRESSO BRASILEIRO DE ÁGUAS SUBTERRÂNEAS. 4., 1986. Anais... Brasília - ABAS/DNAEE/DNPM.

REBOUÇAS, A. da C. Desenvolvimento das águas subterrâneas no Brasil. In: CONGRESSO BRASILEIRO DE ÁGUAS SUBTERRÂNEAS, 10., 2000. Anais... ABAS, Fortaleza.

RIBEIRO, J. A.; VERISSIMO, L. S. (CPRM). Recursos Hídricos e Minerais do Município de Barbalha - CE. 1996. Fortaleza: CPRM, 1996. 50 p., 1996. (Ordenamento Territorial, 2).

RIBEIRO, J. A. O SIAGAS e a gestão dos recursos hídricos subterrâneos. In: CONGRESSO BRASILEIRO DE ÁGUAS SUBTERRÂNEAS, 15,. 2008.

RODRIGUES, J. C. Geologia para engenheiros Civis.1977. São Paulo, McGraw-Hill do Brasil. $210 \mathrm{p}$.

SOUZA, F. S. de; RIBEIRO, J. P. Poço coletor com ponteiras radiais. In: CONGRESSO BRASILEIRO DE ÁGUAS SUBTERRÂNEAS. 4., $\quad 1986 . \quad$ Anais... Brasília, ABAS/DNAEE/DNPM.

SOUZA, L. A. P.; SILVA, R. F.; IYOMASSA, W. S. Métodos de Investigação. In: OLIVEIRA, A.
M. S.; BRITO, S. N. A. Geologia de Engenharia, 1998. ABGE.

SIMABUKURO, E. A. Revestimento geomecânico - metodologia de aplicação. In: CONGRESSO MUNDIAL INTEGRADO DE ÁGUAS SUBTERRÂNEAS, 1., 2000. Anais... Fortaleza, 2000.

STRUCKMEIER, W. F.; MARGAT, J. Hydrogeological Maps - A Guide and a Standard Legend. 1995. Hannover: International Association of Hydrogeologists, (International contribuitions to hydrogeology, v. 17).

TODD, K. D.; MAYS, L. W. Groundwater hydrology, 2005. Third Edition.

TOLMAN, C. F. Ground water. 1937. New York: McGraw Hill, 593p.

US Army Corps of Engineers. Design, Construction, and maintenance of relief wells. 1992, Disponível em: $<$ http://www.publications.usace.army.mil/Portals/ 76/Publications/EngineerManuals/EM_1110-21914.pdf>. Acesso em: 07 jul. 2016.

VERÍSSIMO, L. S. A importância das águas subterrâneas para desenvolvimento socioeconômico do eixo CRAJUBAR, Cariri Ocidental - Estado do Ceará. Fortaleza: UFC, 1999. 128 f. il. Dissertação (Mestrado em Hidrogeologia) - Centro de Ciências, Universidade Federal do Ceará, Fortaleza, 1999.

VASCONCELOS, M. B.; SILVA, C. M. S. V.; SANTIAGO, M. M. F. Aluviões como fonte de suprimento hídrico de pequenas comunidades: um caso do Distrito de São Francisco/MeruocaCE. In: CONGRESSO BRASILEIRO DE ÁGUAS SUBTERRÂNEAS, 12., 2002. Anais... Florianópolis.

VASCONCELOS, M. B.; SILVA, C. M. S. V.; SABADIA, J. A. B. Caracterização das unidades de captação de água subterrânea do Município de Meruoca, Ceará. In: SIMPÓSIO DE GEOLOGIA DO NORDESTE, 20., 2003 Anais... Fortaleza, 2003.

VASCONCELOS, M. B. Abastecimento hídrico e variação sazonal da água subterrânea no município de Meruoca, Ceará. Relatório de Graduação em Geologia, 2004. Universidade 
Federal do Ceará-UFC, Depto de Geologia. 100 p.

VASCONCELOS, M. B. Poços para captação de águas subterrâneas: revisão de conceitos e proposta de nomenclatura. In: CONGRESSO BRASILEIRO DE ÁGUAS SUBTERRÂNEAS, 18., 2014. Anais.., Belo Horizonte, 2014.

VASCONCELOS, M. B.; SOUSA, N. G.; GENARO, D. T.; LUZ, C. A.; TUPINAMBA, M. K. F. Histórico das Perfurações de Poços Tubulares no Estado do Piaúi. Revista de Geologia (Fortaleza), v. 27, p. 111, 2014. Disponível em: <http://www.periodicos.ufc.br/index.php/geologi a/article/view/1296/1228>. Acesso em: 02 jan. 2017.

VASCONCELOS, M. B.; SILVA, C. M. S. V.; SANTIAGO, M. M. F.; SABADIA, J. A. B. Caracterização do Sistema de Abastecimento Hídrico no Município de Meruoca-CE. In: SIMPÓSIO BRASILEIRO DE RECURSOS HÍDRICOS, 15,. 2003. Anais... Curitiba, 2003.
VON SPERLING, E. Afinal, quanta água temos no planeta? Revista Brasileira de Recursos Hídricos, v. 11, p. 189-199, 2006. Disponível em:

<https://www.abrh.org.br/SGCv3/UserFiles/Sum arios/af7a0d2c40a12820c64bf65d88d70b46_ff1a cba4ab30011b1e39f563a50d685b.pdf>. Acesso em: 15 mar. 2016.

WARING, G. A. Suprimento d'água no nordeste do Brasil: açudes, estradas de rodagem, estradas carroçáveis, estradas de ferro construídas e em construção no nordeste brasileiro. 23 ed. [S.L.]: Ministério da Viação e Obras Públicas-Inspetoria Federal de Obras Contra as Seccas, 1923. 78 p.

WATERMAN, E. L. Elements of Water Supply Engineering. 1938. New York: John Wiley \& Sons, Inc.

WESSELS, J. Reviving Ancient Water Tunnels in the desert-Digging for Gold? Journal of Mountain Science, 2005. v. 2, n. 4. Disponível em:

$<$ http://www.romanaqueducts.info/aqualib/qanatli t.html>. Acesso em: 11 jul. 2016. 